\title{
Outcomes Assessment of Pain Relief Techniques Use in Labour in Order to Increase Painless Normal Delivery Rate
}

Sharareh, Khanahmadi ${ }^{*}$

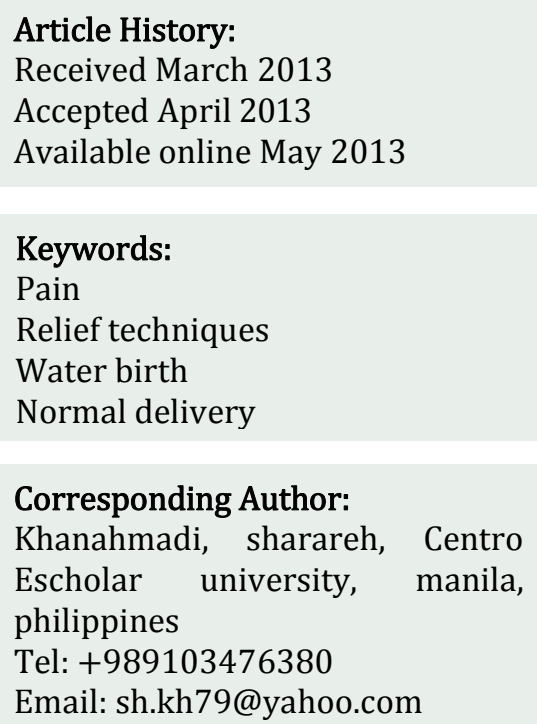

Corresponding Author:

Khanahmadi, sharareh, Centro Escholar university, manila, philippines

Tel: +989103476380

Email: sh.kh79@yahoo.com

\section{Introduction:}

Statistics of world health organization show caesarean section rate has been growing worldwide. According to policy of World Health Organization (W.H.O), the reasonable percentage of caesarean section $(\mathrm{C} / \mathrm{S})$ is 10 $15 \%$ worldwide; however, increased rates of $\mathrm{c} / \mathrm{s}$ are related to additional caesarean deliveries for 0.8-3.2 million in low-income countries and for 4.0-6.2 million in middle and high-income countries. C/S rate is above
$15 \%$ for $50 \%$ of countries on the average (1, $2)$. Although caesarean section must be just performed based on medical indications, elective caesarean rate is rising. Fear of childbirth is one of the most important factors causing women especially nulliparous women to be interested in elective C/S. The severity of this fear depends on many factors, e.g. personality, history and experiences. Since this fear is not decreased even after psychological counselling, it is necessary to relieve the pain of normal delivery by offered methods (3). These pain relief techniques classify as pharmacological and non-pharmacological groups; non-pharmacological group includes methods helping women to cope with pain in labour and pharmacological methods are for relieving the labour pain. Using of Pharmacological methods such as nerve block, opioid drugs and Entonox showed efficient results; however, adverse effects of these methods restrict use of them. Non-medical methods are safer than medical methods due to being non-invasive. Nonpharmacological methods include water immersion, sterile water injection, aromatherapy, manual healing methods

1-Centro Escholar university, manila, Philippines. 
(massage, reflexology), acupuncture, using of music, presence of woman's partner, etc. As most of women require pain relief during labour, using of pain relief techniques would help to progress labour efficiently. Immersion in water, relaxation, massage and acupuncture cause pain relief and satisfaction during labour. The use of forceps is decreased after use of acupuncture and relaxation. Furthermore, acupuncture decreases the rate of $\mathrm{C} / \mathrm{S}$. Reflexology and massage as manual methods could cause to reduce pain and to improve emotional experiences of the labour. These methods could be done by trained midwives. Other manual methods include osteopathy, shiatsu and zero balancing, etc(4). Studies about acupuncture and sterile water injection showed pain relief and relaxation with acupuncture and just pain relief with sterile water injections, but the problem about acupuncture method was unawareness of midwives about performing this method. Therefore, training the midwives about methods appears to be necessary (5). Intracutaneous or subcutaneous injection of sterile water as a pain relief method has been using recently. The beneficial and noticeable effects of this method include fewer side effects than other methods, no need to advanced equipment and easy to do. In one study, low back pain was reported after using of this method, but more advanced researches is essential to confirm this effect (6).Warm shower as a non-pharmacological and easy method helps mother to participate in birthing process, to feel convenient, and to be under support. Moreover, this method has positive and hygienic effects for mother (7). Effects of the presence of Family Members as a pain relief factor has been assessed recently; Since anxiety is a common problem that most of women confront it in delivery process, presence of woman's partner or friend could be effective in decreasing the anxiety psychologically; however, further studies for supporting this study appears to be needed (8). Maternal Positions during second stage of labour could control pain relief as well and labour progress. Although upright posture of mother decreases the need of epidural anaesthesia, it increases the risk of blood loss greater than $500 \mathrm{~mL}$. However, various positions are offered during labour in order to relieve pain, mother choice and safety of baby determines the best position for mother (9). Among pharmacological methods for pain relief, Local anaesthetic nerve block (pudendal, paracervical and epidural block) is more effective than opioid drugs, e.g. intramuscular pethidine and fentanyl. Para cervical block is mainly used during the first stage of labour, but pudendal block is used in the second stage of labour. Even though local anaesthetic nerve block could cause pain relief during labour, there are probably some side effects with them, including decreased fetal heart rate, sweating and giddiness after using this method that restrict use of this method in comparison to non-medical pain relief techniques. Side effects of Epidural block are hypotension, fever, urine retention, more using of forceps or ventouse and motor blocks. Probably, parenteral opioids are less effective than epidural block; however, further studies are essential to compare the outcomes and effects of this technique with and various pain relief techniques in labour. Inhaled nitrous oxide and oxygen (Entonox) as one of the pharmacological methods cause to relieve pain during labour; however, reports indicates feeling of drowsy, nauseous and sickness in some women $(10,11)$. 


\section{References:}

1.Gibbons L, Belizán JM, Lauer JA, Betrán AP, Merialdi M, Althabe F. The global numbers and costs of additionally needed and unnecessary caesarean sections performed per year: Overuse as a barrier to universal coverage world health report. Background Paper, No 30, Geneva: Switzerland, 2010. Available from URL:

http://www.who.int/healthsystems/topics/financing/healthreport/30C-sectioncosts.pdf Accessed 28 May 2011.

2. Atan Ş. Ü, Duran E. T, Kavlak O, Donmez S, \& Sevil U. Spontaneous vaginal delivery or caesarean section? What do Turkish women think?. International journal of nursing practice 2013; 19(1): 1-7.

3.Sydsjö G, Sydsjö A, Gunnervik C, Bladh M, \& Josefsson A. Obstetric outcome for women who received individualized treatment for fear of childbirth during pregnancy. Acta Obstetricia et Gynecologica Scandinavica 2012; 91(1): 44-49.

4. Smith, C. A., Levett, K. M., Collins, C. T., \& Jones, L. Massage, reflexology and other manual methods for pain management in labour. Cochrane Database Syst Rev 2012, 2.

5. Mårtensson L, \& Wallin G. Use of acupuncture and sterile water injection for labor pain: a survey in Sweden. Birth 2006; 33(4): 289-296

6. Derry S, Straube S, Moore R. A, Hancock H, \& Collins Sally L. Intracutaneous or subcutaneous sterile water injection compared with blinded controls for pain management in labour. Cochrane Database Syst Rev 2012, 1.

7. Lee S. L, Liu C. Y, Lu Y. Y, \& Gau M. L. Efficacy of Warm Showers on Labor Pain and Birth Experiences During the First Labor Stage. Journal of Obstetric, Gynecologic, \& Neonatal Nursing 2013; 42(1): 19-28.

8. Chunuan S, Somsap Y, Pinjaroen S, Thitimapong S, Nangham S, \& Ongpalanupat F. Effect of the presence of family members, during the first stage of labor, on childbirth outcomes in a provincial hospital in Songkhla Province, Thailand. Pacific Rim International Journal of Nursing Research 2013; 13(1): 16-27.

9. Kemp E, Kingswood C. J, Kibuka M, \& Thornton J. G. Position in the second stage of labour for women with epidural anaesthesia. Cochrance Database of systemic reviews. 2013, 1 .

10. Novikova N, \& Cluver C. Local anaesthetic nerve block for pain management in labour. Cochrane Database Syst Rev 2012, 4. 
11. Jones L, Othman M, Dowswell T, Alfirevic Z, Gates S, Newburn M, et al. Pain management for women in labour: an overview of systematic reviews. Cochrane Database Syst Rev 2012, 3. 